\title{
Discrete Event Modelling for Evaluation and Optimisation of Power Utility Energy Demand
}

\author{
Megashnee Munsamy (iD, Arnesh Telukdarie iD \\ University of Johannesburg (South Africa) \\ mmunsamy@uj.ac.za,arnesht@uj.ac.za
}

Received: May 2021

Accepted: October 2021

\begin{abstract}
:
Purpose: The cost and environmental impact of energy is driving better quantification of energy utilization in a business context. Determining an entire business electrical energy usage, inclusive of core operations and support activities, in a singular evaluation protocol is a challenge. The challenge is exasperated when changes occur in the business, where every change implies significant rework of the business energy calculations. This study develops a holistic energy determination model for the entire business requiring minimum inputs for energy re-calculation, when aspects of the business changes.
\end{abstract}

Design/methodology/approach: The research adopts a quantitative approach enabled through a Discrete Event Model. The model is developed based on the activities performed in every functional area of the business. The activities are captured using business process science. The processes are then developed into a DES Model. The model development cycle includes data collection, model development and configuration, model validation and scenario models for optimization.

Findings: A coal fired power generation business, with multiple sites is comprehensively simulated to evaluate the baseline electrical energy demand and associated $\mathrm{CO}_{2}$ emissions. The results are captured at various levels of the business including; Enterprise; site, business function and equipment level. The generation sites operational functions are identified as major electrical energy consumers. The adoption of Industry 4.0 technologies of Internet of Things, Big Data Analytics, mobility and automation demonstrate energy savings of $1 \%$ of total site demand. As the Industry 4.0 technologies are applied to a limited number of processes, the results demonstrate the capability of these technologies having a significant impact on electrical energy demand and $\mathrm{CO}_{2}$ emission when applied to a broader spectrum of business processes.

Research limitations/implications: The research is limited to a multi-site energy generating company, which is a coal to energy business.

Practical implications: The research has significant practical implications, mostly on the mechanisms to evaluate business energy utilisation. The ability to include all areas of the business is a key practical differentiator, as compared to traditional models focusing on operations only.

Originality/value: The model is unique in that it is a model that is system agnostic to any production configuration, most especially changes in configuration. This implies that the model can be easily and quickly adapted with changes in the business. This implies the model proposed would be significantly more adaptable when compared to traditional approaches.

Keywords: business systems, fourth industrial revolution, modeling, energy 


\section{To cite this article:}

Munsamy, M., \& Telukdarie, A. (2022). Discrete event modelling for evaluation and optimisation of power utility energy demand. Journal of Industrial Engineering and Management, 15(1), 124-141. https://doi.org/10.3926/jiem.3606

\section{Introduction}

Energy is considered a necessity in today's society. It contributes to every aspect of daily life including; access to clean and safe drinking water; communication, quality healthcare and food. This is further affirmed by the United Nations Sustainable Development Goal 7, which states "Ensure access to affordable, reliable, sustainable and modern energy for all"(United Nations, 2020). The economic and social growth of developing countries is significantly contributing to the rise in global energy demand (Aslani \& Mohaghar, 2013). Rentsch and Heinzel (2015) state that energy consumption is on the rise globally, and not only in digitalised and developing countries.

Traditional power generation has been via fossil fuels such as coal and natural gas, which has detrimental impacts on the environment (Peng, Chen \& Yao, 2021). Whilst the transition to renewable energy sources is rapidly expanding, coal remains a significant fuel source (Feng, Yang, Hou, Duan, Yang \& Wang, 2021), accounting for $36 \%$ of global power generation (IEA, 2020a). The existing power plants generate $30 \%$ of global energy related $\mathrm{CO}_{2}$ emissions (IEA, 2019). Further to this, the existing coal fired power generation fleet is fairly young, with $60 \%$ of power generation stations less than 20 years (IEA, 2020a), and an additional 170MW is under construction (IEA, 2019). Whilst there is a decline in use of coal for power generation in Europe and North America, South East Asia is emerging as a key region for growth of coal power generation (Clark, Zucker \& Urpelainen, 2020; Gagarin, Sridhar, Lange \& Bazilian., 2020). It is estimated that global carbons emissions due to power generation will increase to $42 \%$ by 2040 (Feng et al., 2021).

The past and present investments in coal power generation necessitates efficiency improvements (IEA, 2020a). Fostering energy efficiency offers a cost effective approach to GHG emissions reduction (Sun, Edziah, Sun \& Kporsu., 2021). Many governments have strategic policies to drive renewable energy diffusion, and to reduce to high-energy intensities, (Sun et al., 2021). In 2019 the US Department of Energy invested 38 million dollars towards improvement of power plant performance (IEA, 2020a). The Fourth Industrial Revolution delivers significant optimization options for coal power generation facilities, including increased operational flexibility towards integration of renewable technologies (IEA, 2017). However, implementation of Fourth Industrial Revolution (4IR) technologies and processes comes with additional energy requirements. This additional energy requirements are offset by the higher energy efficiencies achieved.

There are various mechanisms for analysing and improving the performance of energy systems, with energy modelling being among the most established (Bhattacharyya \& Timilsina, 2010; Jebaraj \& Iniyan, 2006). The energy models typically applied at power generation sites are at the process and equipment level. These models are highly specific, and data intensive (quantitative and disaggregated data), and proprietary (Munsamy, Telukdarie \& Fresner, 2019). There is a notable gap at the business level, as business functions such as maintenance, logistics, planning, HR and finance are excluded.

This research propositions an energy optimization model, based on business processes and Discrete Event Simulation (DES), for power producers. The model includes all equipment demand, activity-based demand and buildings energy demand.

\section{Literature Review}

Electricity, is the fastest growing final energy source, but there is approximately 1 billion people without access to electricity (IEA, 2020b). Power generation companies are typically large, multinational enterprises or government owned entities as the cost of construction (inclusive of planning and designing) and operation is significant and have long operational lifespans. These companies operate multiple generation, distribution and support service sites 
globally, and are thus required to adhere to varying labour and environmental regulations (specific per country) and manage large staff contingents.

Coal is still a significant source for power generation (Feng et al., 2021), and with $60 \%$ of coal fired power generation stations less than 20 years, efficiency improvements are critical (IEA, 2020a). Energy modelling is a tool widely applied in the management and optimization of energy systems (Bhattacharyya \& Timilsina, 2010; Herbst, Tor, Reitze \& Jochem 2012). Various power suppliers and their service providers including Aspen, Rockwell Automation, General Electric (GE), Honeywell, ABB and Schneider Electric, have developed energy models and tools. The models and tools may be applicable to different industries such as; Aspens Energy Analyzer for optimization of heat exchanger networks (Aspen Technology Inc., 2021a) and Aspen Utilities for optimization of energy use and reduction of emissions and costs (Aspen Technology Inc., 2021b), or specific to an industry such as GE PSLF Simulation Engine, which is applicable to the power industry and some of its capabilities include stability analysis and thermal and voltage analysis (GE, 2019). Key characteristics of these models include: specificity of application, it is typically focused on a single area of application or a specific type of equipment; having a specific objective such as utilities optimization; requiring quantitative and highly disaggregated data; requiring users with a moderate to high engineering and/or technical proficiency and the software are proprietary (Munsamy et al., 2019). A key limitation of these models are the specificity to a process or equipment, typically on the operational side, thus unable to provide a complete business energy evaluation, inclusive all business activities.

The Fourth Industrial Revolution is presenting new opportunities for the power generation sector. Digitalization has the potential to revolutionize the current energy sector; the capability to identify the energy user, supply the user with the required energy at the right time and place and at the lowest cost (IEA, 2017). Digitalization could potentially save the power sector 80 billion US dollars per year (IEA, 2017), through improved power plant efficiency, reduction in operations and maintenance costs and unplanned outages. Potential improvements due to application of digital technologies include: prediction of Heat Recovery Steam Generator (HRSG) tube leaks; identification of valves requiring repair or replacement by utilizing smart meters; increased accuracy of modelling of operational functions by using machine learning; real time notification to personnel of order and updates; training and real time tracking of performance via augmented and virtual reality and heat-rate improvements up to 3\% by use of machine learning (Guzman, Prasanna, Safarik \& Tanwar., 2019).

Whilst, power generation companies provide an essential service of electricity generation, it is still a business. A business is an entity that seeks to profit from activities by offering specific goods or services to customers. (Temponi, Bryant \& Fernandez, 2009), defines a business as a dynamic set of interacting elements, inclusive of technical processes, organisational processes, technical functions, departments, business centres and subsystems like finance, production, marketing, and management. A business comprises functional areas, hierarchical organisation from management to knowledge workers, and corporate strategic vision or goals that need to be fulfilled through timeous execution of operations or activities (Moeuf, Pellerin, Lamouri, Tamayo-Giraldo \& Barbaray, 2017). Existing conventional approaches to value creation are no longer enough in handling increasing requirements pertaining to cost, efficiency, flexibility, adaptability, stability and sustainability (Hofmann \& Rusch, 2017). Yao, Xiao, Jian and Shu (2021) state that electricity companies need to urgently develop models that guide their decisionmaking processes, and governments need models to guide low-carbon policies. To enable informed decision making, the business must be represented holistically and comprehensively, inclusive of all business cross-links, interdependencies, and deviations.

Business processes, which detail the sequence of steps in execution of business activities (Bititci \& Muir, 1997), is a common business management tool. The business activity is any activity conducted by the business; boiler operation, steam turbine start-up, ordering of goods/services, maintenance of pump; recruitment of personnel and upgrading of ICT systems. Business processes are inherently detailed, technical and while being sequential also includes parallel operational paths, cross-links with other business processes and decision blocks. Decision blocks determine the business process path to be followed when there are multiple parallel paths. Examples of decision blocks include; did the coal pass the quality test, is the equipment under maintenance a statutory equipment, with each possible answer following a different process path. Cross-links indicate the interdependencies of the business 
processes; the generation schedule is interlinked to the maintenance plan and inventory management business processes.

Business Process Simulation (BPS) evaluates the performance of a business activity under multiple scenarios, thus allowing comparative analysis towards identification of best operational practices (Camargo, Dumas \& Gonzalez-Rojas, 2020). BPS enables computation of various performance measures such as cycle time, resource utilisation, and waiting times for each task in the process. As business processes detail the sequence of tasks in execution of business activities, the simulation of business processes is Discrete Event Simulation.

Discrete Event Simulation (DES) models a system as a sequence of events (Agalianos, Ponis, Aretoulaki, Plakas \& Efthymiou, 2020). Paulista, Peixoto and de Assis-Rangel (2019) applied DES in evaluating the electrical energy consumption and generation at a diary plant. Kohl, Spreng and Franke (2014) applied DES to evaluate the energy demand of individual products and their variants. Keshari, Sonsale, Sharma and Pohekar (2018) applied DES to quantify and comparatively analyze the energy demand of a paper and pulp plant under varying operational conditions. Cataldao, Taisch and Stahl (2013) applied DES in evaluating the energy demand of a production line, comprising of four operating machines. The energy demand of the whole plant and each machine is analyzed. DES is also used to solve issues that involve continuous approaches such as energy flow or in industries based on pipeline network fluids (Ekyalimpa, Werner, Hague, AbouRizk \& Porter 2016). DES is an established method to support decision making for planning tasks in production and logistics and is mostly established in large enterprises (Lang, Reggelin, T., Muller, B., \& Nahhas, 2021). May, Barletta, Stahl, \& Taisch (2015) affirmed that DES can be used to verify behaviour of energy consumption in different production scenarios, thus providing decision making resources regarding the energy contract to be made with the local concessionaire. The numerous applications of DES in energy management and optimization supports its adoption in this research. This research adopts business processes as the basis for DES towards development of a comprehensive (inclusive of all business activities) energy optimization model for a power generator.

\section{Methodology}

For power generation companies to achieve its mandate, of generation and distribution of electricity to end users, the following business functions are required: Strategy (SR); Integrated Planning (IP); Logistics (Log); Sales and Marketing (S\&M); Customer Service Management (CSM); Human Resources (HR); Information and Communication Technologies (ICT); Financial Management (FM); Power Production (PP), Transmission (T); Distribution (D); Maintenance (Main); Research and Development (R\&D), Develop Product and Services (DPS) and Safety, Health, Environment, Quality and Risk (SHEQR). The aforementioned is a high level functional area representation, with each of these functional areas delineated into various process areas and finally into business processes. As each business process is linked to a specific functional area, a business process hierarchy is developed. In developing the business process hierarchy for the power generation company, the following established business process hierarchies were considered; ARIS (Davis \& Brabander, 2007), SAP (SAP, 2016) and APQC Process Classification Framework (PCF) (APQC, 2015). A four-level hierarchy is developed for a power generation company, as detailed below:

- Level 0 - Functional area: Is the highest level of the business such as Power Production, Human Resources and Financial Management.

- Level 1 - Process Area: Is the categorisation of activities within a functional area, such as Recruitment within the Human Resources function.

- Level 2 - Business Process: Details the sequences of tasks for a specific business activity such as recruit candidates.

- Level 3 - Business Process Step: Is a single step of the business process such as post advert on the selected mediums for the recruit candidate business process.

A screen and select candidate business process, which is part of the Human Resources function, is illustrated in Figure 1. 


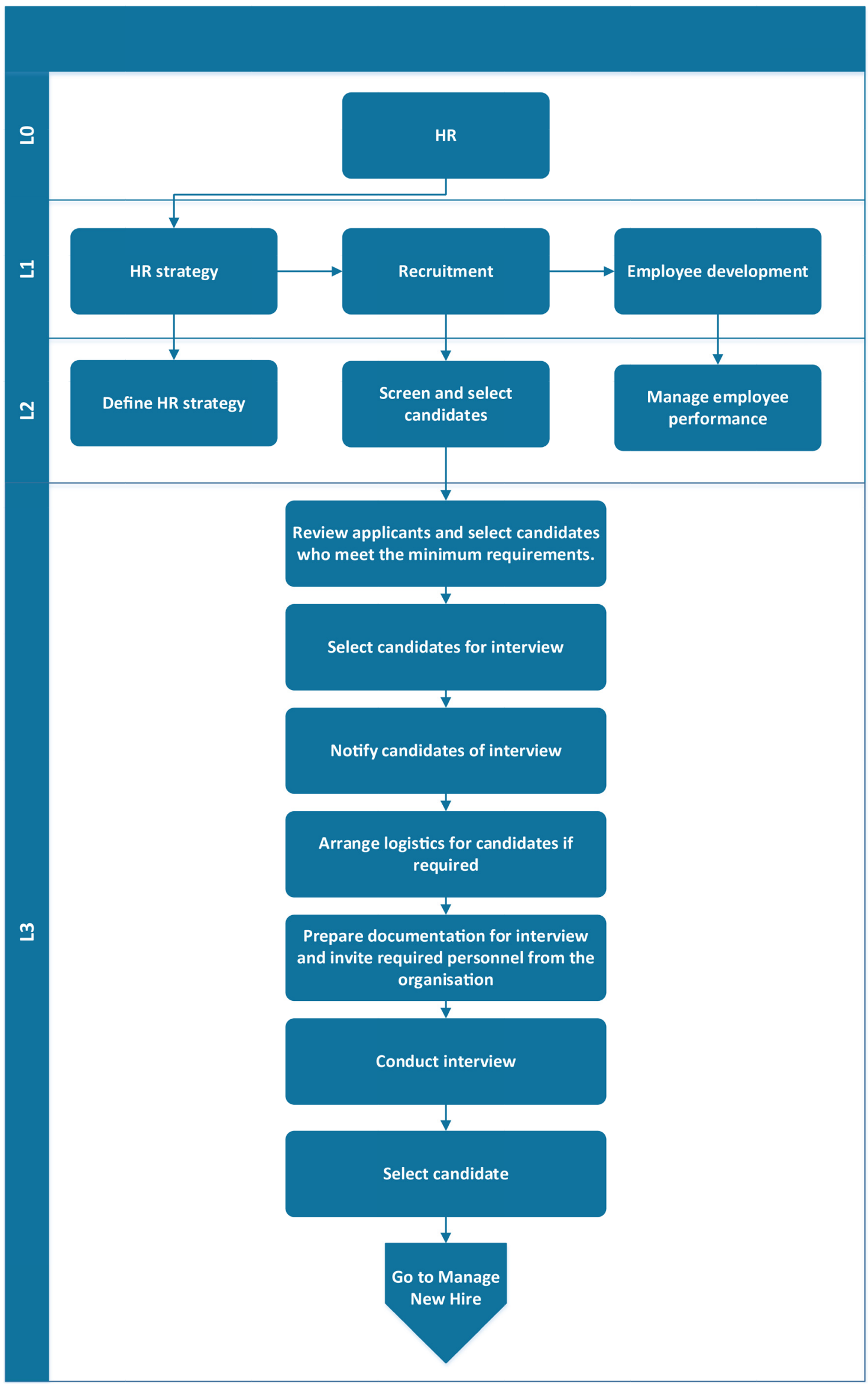

Figure 1. Screen and select candidate business process 
At Level 3 of business process step, the execution details are explicit, refer to Figure 1. This facilitates quantification of resource requirements of personnel, raw material, equipment (process and ICT), resource utilisation time and task execution time. This data is utilised in quantifying the energy demand and $\mathrm{CO}_{2}$ emissions of the power generation company, as per Equations 1 and 2 (Munsamy et al., 2019; Munsamy \& Telukdarie, 2021).

$$
\text { Company Electrical Energy Demand }=\sum_{1}^{\mathrm{j}} \sum_{1}^{\mathrm{k}} \sum_{1}^{1} \sum_{1}^{\mathrm{m}} \sum_{1}^{\mathrm{n}} \sum_{1}^{\mathrm{o}} \begin{aligned}
& \text { Resource Energy Demand } \\
& { }_{*} \text { Resource Utilisation Time }
\end{aligned}
$$

The execution structure of Equation 1 enables analysis of energy demand and $\mathrm{CO}_{2}$ emissions at various business resolutions: business process, process area, business function, site level and company level, facilitating effective optimisation.

$$
\text { Company } \mathrm{CO}_{2} \text { Emissions }=\sum_{1}^{\mathrm{j}} \sum_{1}^{\mathrm{k}} \sum_{1}^{\mathrm{l}} \sum_{1}^{\mathrm{m}} \sum_{1}^{\mathrm{n}} \sum_{1}^{\mathrm{o}} \begin{aligned}
& \text { Resource Energy demand } \\
& \mathrm{CO}_{2} \text { Emissions factor }
\end{aligned}
$$

Where

$o=$ Number of resources

$n=$ Number of business process steps

$m=$ number of business processes

$l=$ number of process areas

$k=$ number of functional areas

$j=$ number of sites

\begin{tabular}{|c|c|c|c|c|c|c|}
\hline $\begin{array}{l}\text { Business } \\
\text { Process }\end{array}$ & Business Process Step & Resource & $\begin{array}{l}\text { Resource } \\
\text { Energy } \\
\text { Demand (W) }\end{array}$ & $\begin{array}{l}\text { Number of } \\
\text { Resources } \\
\text { Required }\end{array}$ & $\begin{array}{l}\text { Resource } \\
\text { Utilisation } \\
\text { Time (hr) }\end{array}$ & $\begin{array}{l}\text { Energy } \\
\text { Demand } \\
\text { (Wh) }\end{array}$ \\
\hline $\begin{array}{l}\text { Screen and select } \\
\text { candidates }\end{array}$ & $\begin{array}{l}\text { Review applicants and select } \\
\text { candidates who meet the criteria. }\end{array}$ & Laptop & 30 & 4 & 1.00 & 120 \\
\hline $\begin{array}{l}\text { Screen and select } \\
\text { candidates }\end{array}$ & Select candidates for interview & Laptop & 30 & 1 & 0.50 & 15 \\
\hline $\begin{array}{l}\text { Screen and select } \\
\text { candidates }\end{array}$ & Select candidates for interview & Printer & 2287 & 1 & 0.03 & 76 \\
\hline $\begin{array}{l}\text { Screen and select } \\
\text { candidates }\end{array}$ & Notify candidates of interview & Laptop & 30 & 1 & 0.17 & 5 \\
\hline $\begin{array}{l}\text { Screen and select } \\
\text { candidates }\end{array}$ & Arrange logistics for candidates & Laptop & 30 & 1 & 0.33 & 10 \\
\hline $\begin{array}{l}\text { Screen and select } \\
\text { candidates }\end{array}$ & $\begin{array}{l}\text { Prepare documentation for } \\
\text { interview and invite required } \\
\text { personnel from the organisation }\end{array}$ & Laptop & 30 & 2 & 2.00 & 120 \\
\hline $\begin{array}{l}\text { Screen and select } \\
\text { candidates }\end{array}$ & $\begin{array}{l}\text { Prepare documentation for } \\
\text { interview and invite required } \\
\text { personnel from the organisation }\end{array}$ & Printer & 2287 & 1 & 0.08 & 191 \\
\hline $\begin{array}{l}\text { Screen and select } \\
\text { candidates }\end{array}$ & Conduct interview & Laptop & 30 & 1 & 1.00 & 30 \\
\hline $\begin{array}{l}\text { Screen and select } \\
\text { candidates }\end{array}$ & Select candidate & Laptop & 30 & 1 & 1.00 & 30 \\
\hline
\end{tabular}

An illustration of the execution of Equations 1 and 2 are illustrated in the Table 1.

Table 1. Calculation of energy demand for the screen and select candidate business process 
The simulation of the energy demand and associated $\mathrm{CO}_{2}$ emissions at the lowest level of Level 3, is rolled up to the proceeding levels, enabling analysis at each categorised business level and the business as a whole. The approach for quantifying and optimising the energy demand is illustrated in Figure 1. The initiation point for model execution is the business process/es for simulation (extracted from the database), as illustrated in Figure 1 and Table 1. The business processes database is developed in Microsoft Visio and structured as per the business process hierarchy.

The next step is determination of the resources required for execution. Due to the vast resource requirements of a power generation company, the resources are functionally categorised; ICT (inclusive of hardware and network devices), process (boiler, steam turbines, fans) and Building Technical Services (BTS). BTS includes the HVAC, and lighting demand of the various buildings/facilities at each site. As the HVAC and lighting demand is dependent on the space function such as canteen, meeting room, office space and plant operations, the HVAC and lighting demand are calculated per space type. For each resource category, the resources are further classified based on design parameters; boilers are further categorised as sub-critical, critical or super critical. This categorisation structure enables each resource to have a unique identifier for ease of database management and extraction of data. The data sources included: open source data such company annual reports, supplier brochures and equipment specification sheets; peer-reviewed publications; white papers and reports from established organisations such as the International Energy Association. For simulation of each business process step, the resources are extracted from the resources databases developed in Microsoft Excel.

For simulation of the energy demand and $\mathrm{CO}_{2}$ emissions, the model is coded in Microsoft Excel Visual Basic Application (VBA). Microsoft Excel VBA is selected due to its compatibility and ease of integration with Microsoft Excel and Visio. In simulation of the energy demand and $\mathrm{CO}_{2}$ emissions, the exact state of every business variable cannot be accurately predicted due to the dynamics of the business and external factors effecting business operations. This is especially relevant in simulating decisions blocks, which determines the process path flow followed. Considering the decision block, "Did the coal pass the quality test?" it is challenging to accurately predict exactly how many coal quality tests are passed and failed due to various external factors. Thus in simulation of the decision blocks, the model applies the Random Function constrained to the upper and lower limit operational range. The application of the Random Function introduces noise to the model. Monte Carlo Simulation handles variables as stochastic variables (Bonate, 2001). Monte Carlo Simulations are applied to limit the influence of the Random Function. The Monte Carlo Simulations are executed until the baseline state is achieved, which is defined as a negligible change in the Standard Error of the Mean (SEM) of the simulated energy demand. Due to the number of operational sites of a power generator, the Monte Carlo Simulation is initially run for the site with the largest number of decisions, as the greater the number of decision blocks the greater the variability. The number of simulations required to achieve negligible change in the Standard Error of the Mean, is applied for the remaining sites. The median values of all the Monte Carlo Simulation (until negligible change in SEM) is applied in determining the baseline energy demand and $\mathrm{CO}_{2}$ emissions.

Optimisation is simulated by substituting current business processes with optimised business processes and/or by technology substitution. An optimisation database is developed, comprising the:

- Re-engineered business processes: Business processes which have been modified by adoption of digital technologies, energy efficient technologies and "smart" resources.

- Resources: Includes "smart" resources such as smart meters, and green or efficient technologies such as variable frequency drives and low NOx burners.

The user would select the appropriate option/s from the database. The user can select a re-engineered business process such as an Internet of Things Enabled Production Tracking business process, where radio frequency identification tags are attached to equipment for real time capturing of process information, that support decision making on process operations. Alternatively, the user can select a specific resource such as the use of variable frequency drive, with the model replacing all conventional motors with variable frequency drives for the specific business process. This approach enables comparative analysis between the as-is and optimised processes. 
The increasing availability of advanced technologies results in multiple optimisation options. However the use of these technologies is limited to a company's financial and resource capacity. To determine the optimisation option with the greatest impact to the objective of reduction of energy demand and associated $\mathrm{CO}_{2}$ emissions, the Design of Experiment (DOE) methodology is applied. The DOE methodology evaluates the optimisation options singularly and in combinations to determine which option/s results in the highest energy and $\mathrm{CO}_{2}$ emissions reduction.

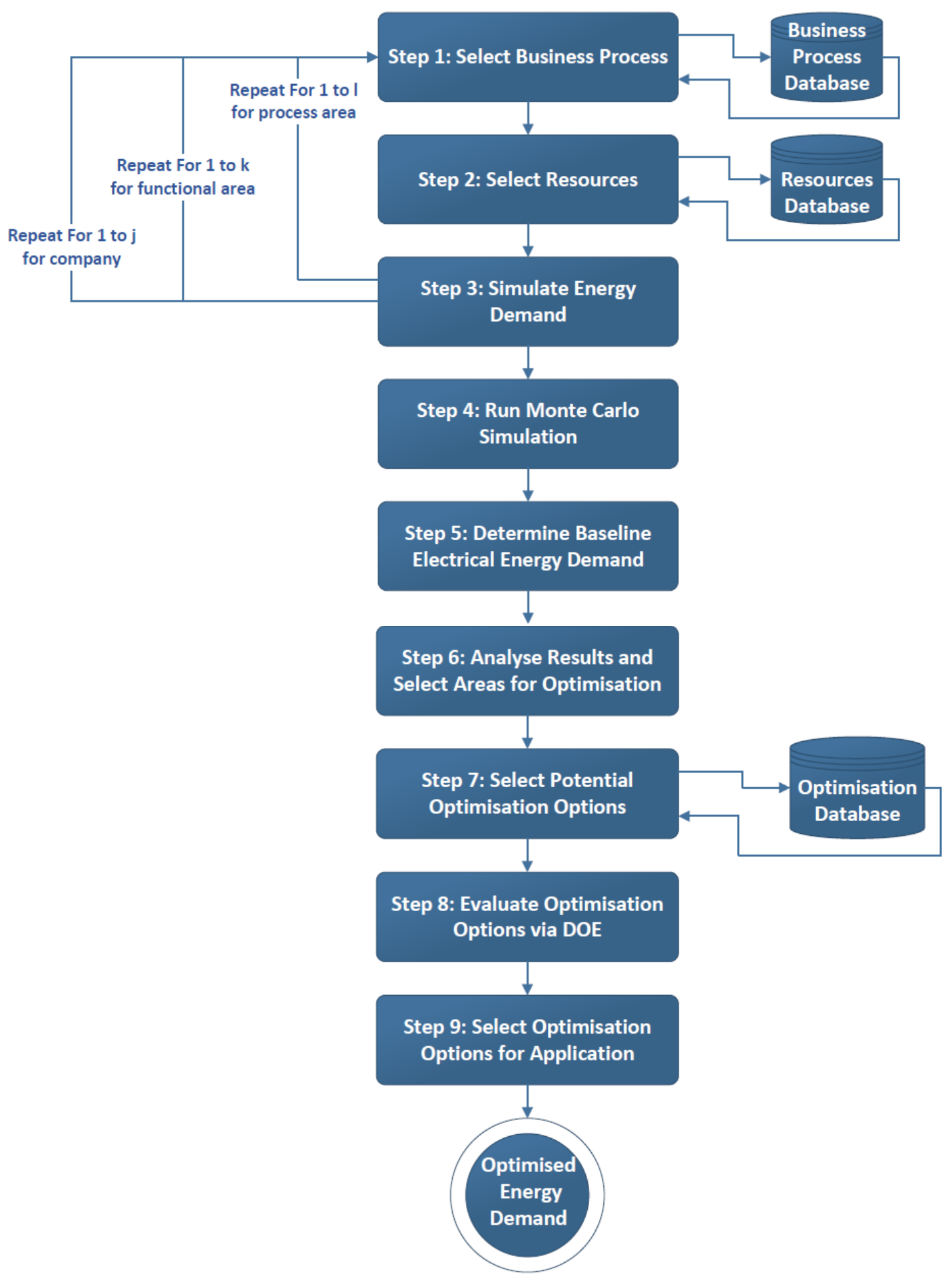

Figure 2. Energy modeling approach 


\section{Results}

The application of business processes for discrete event modelling simulation in quantifying and optimising electrical energy is demonstrated via application to a power generating company comprising three operational sites, with each site in a different geographic location. The sites are: Corporate site; Generation Site 1 with a generation capacity of $3600 \mathrm{MW}$ and Generation Site 2 with a generation capacity of $3000 \mathrm{MW}$. The corporate site establishes the vision, strategy and policies of the company and executes functions such as HR, S\&M, CSM, ICT, R\&D and FM.

Generation sites 1 and 2 produce electricity via coal fired boilers and execute support functions such as HR, Logistics, Maintenance, ICT, SHEQR and FM. Generation Site 1 produces electricity via six 600MW boiler, with a coal feed rate of 1800 ton/hr. Generation Site 2 produces electricity via six 500MW boiler, with a coal feed rate of $1400 \mathrm{ton} / \mathrm{hr}$. For the power production function, only the steam generation process from coal delivery to steam turbine is simulated. The balance of plant operations of water treatment, transformer and generator are excluded due to limited access to operational data. In evaluating the electrical energy demand it is assumed the coal mines are in close proximity to the respective generation sites allowing the transfer of coal from the mine to the generation sites via a conveyor belt system. The resource requirements for the power production process include but not limited to; conveyor belts, boilers, turbines, various types of pumps and fans, electrostatic precipitators, control systems, instrumentation and coal mills. Both of the generation sites have 83 decision blocks each, varying from, "the number of coal samples that pass the quality test" to "does the material inventory meet the planned production requirements." Generation Site 1, with the higher generation capacity of $3600 \mathrm{MW}$, was simulated first to determine the number of Monte Carlo Simulations. For Generation Site 1, at 4600 simulations the change in the standard error of the mean of the electrical energy demand is negligible. Thus for Generation Site 2 and the Corporate Site, the Monte Carlo simulations are run 4600 times each.

Each site's electrical energy demand is cumulative of the business activities (executed as per the business process), Building Technical Services (BTS) and network requirements. The energy demand of all three sites is evaluated on an annual basis, with the results detailed below.

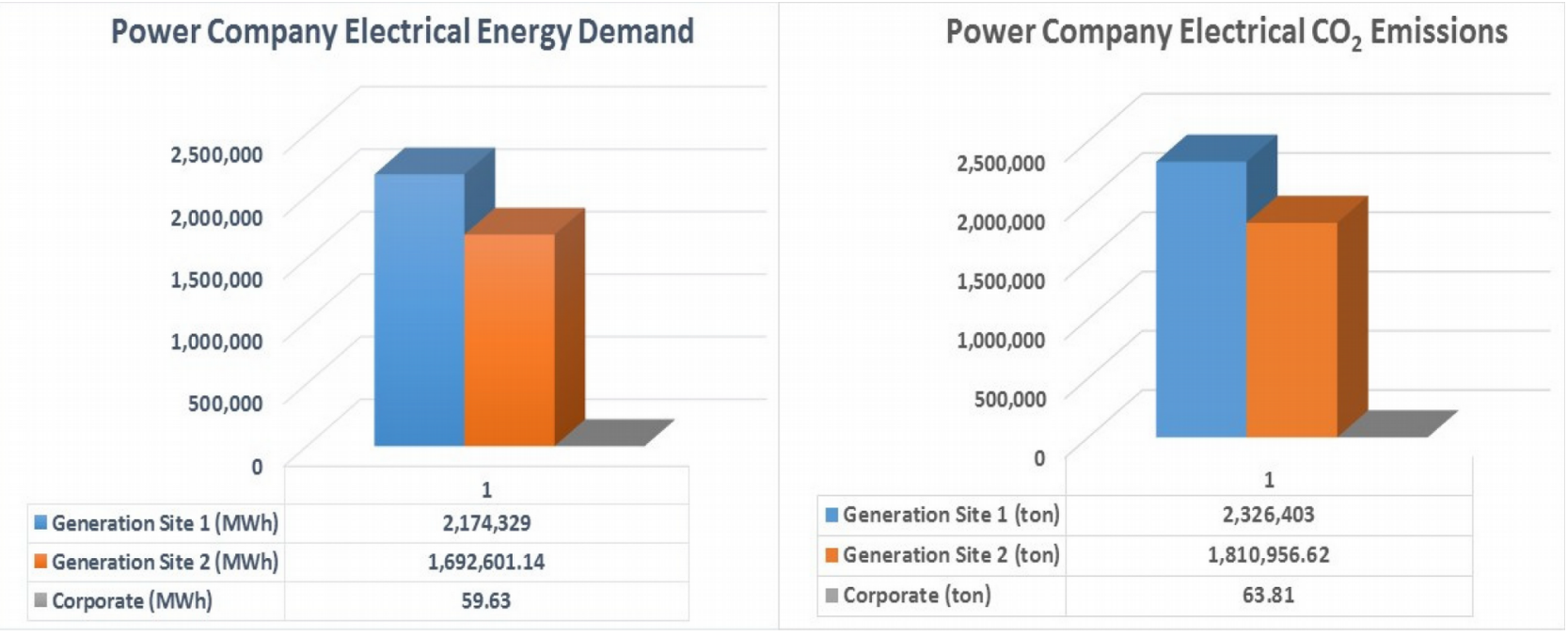

Figure 3. Electrical energy demand and $\mathrm{CO}_{2}$ emissions of each site

Figure 3 illustrates that the generation sites are the largest contributors to the company's electrical energy demand, as expected. Generation site 1 has a $22 \%$ higher electrical energy demand, due to a higher generating capacity of $3600 \mathrm{MW}$ as compared to $3000 \mathrm{MW}$ of generation site 2 .

The second level of analysis is at the functional level (Level 0 as per the business process hierarchy), as illustrated in Figure 4 . In the following graphical illustrations $p$ refers to primary axis and $s$ to secondary axis. 


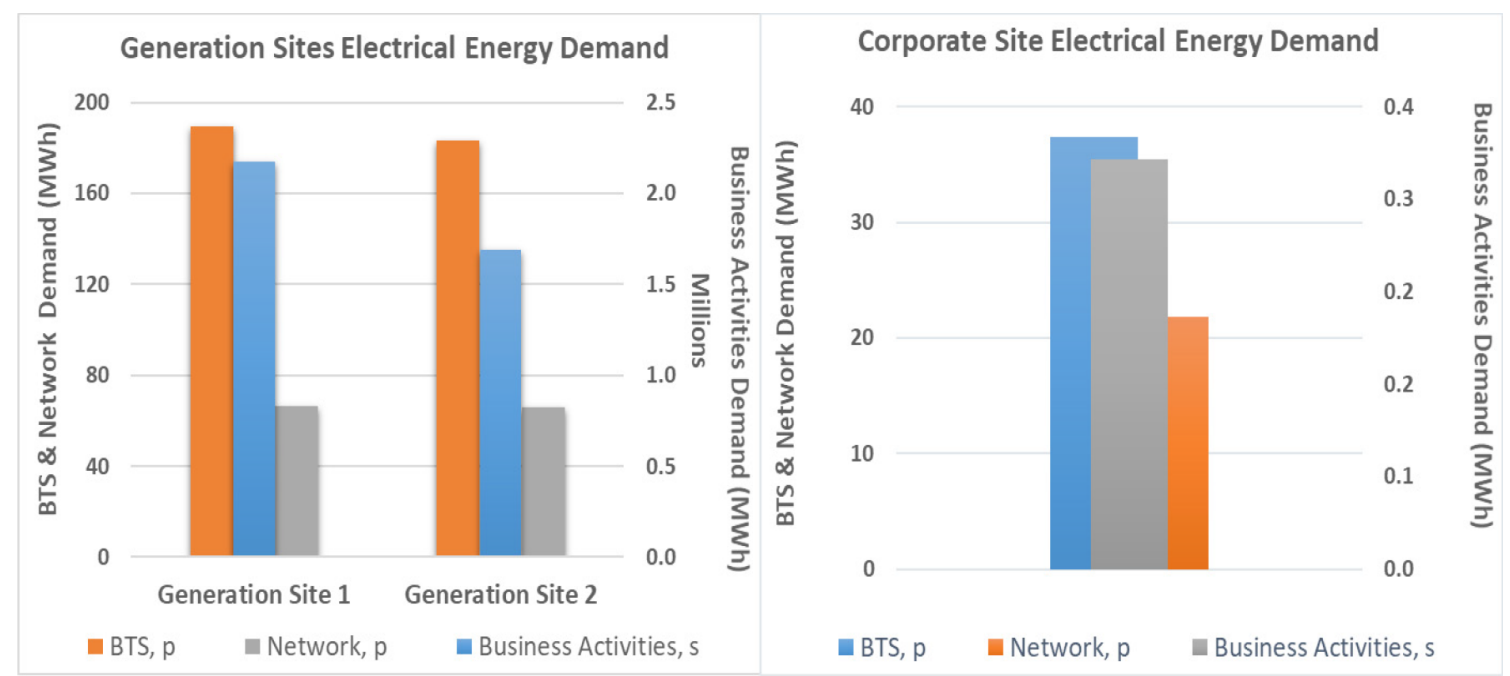

Figure 4. (a) Generation site electrical energy demand profile. (b) Corporate site electrical energy demand profile

The generation sites electrical energy demand is five to six times greater than that of the corporate site, as illustrated in Figure 4. At the generation sites, the largest consumer of the electrical energy demand are the business activities, which encompasses all activities executed including power production. For the generation sites, BTS has the second highest electrical demand followed by network, refer to Figure 4(a). At the corporate site, the largest contributor is BTS, followed by network and business activities, respectively.

For the functional area analysis, the generation sites are evaluated separately from the corporate site due to the difference in scale of electrical energy demand. Further to this, for the generation sites the power production functional area electrical energy demand is excluded from Figure 5, due to its significantly larger energy demand in comparison to the other functional areas. The functional areas illustrated in Figure 5, can be considered as support functions to power production.

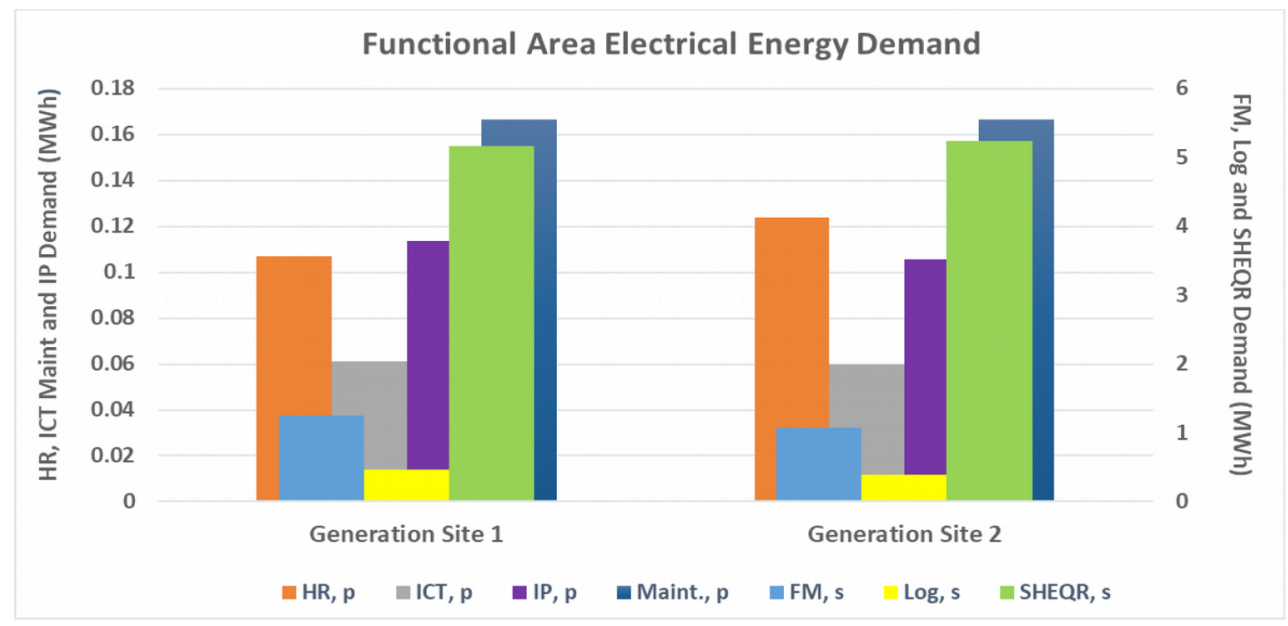

Figure 5. Electrical energy demand of the various functional areas at each generation site

The SHEQR functional area has the highest electrical energy demand, attributed to the frequent quality testing, such as coal quality testing. This is followed by the financial management and logistics functions, respectively. The voluminous repetitive tasks of the financial management function such as payment of suppliers and staff, results in it having the second highest electrical demand. 


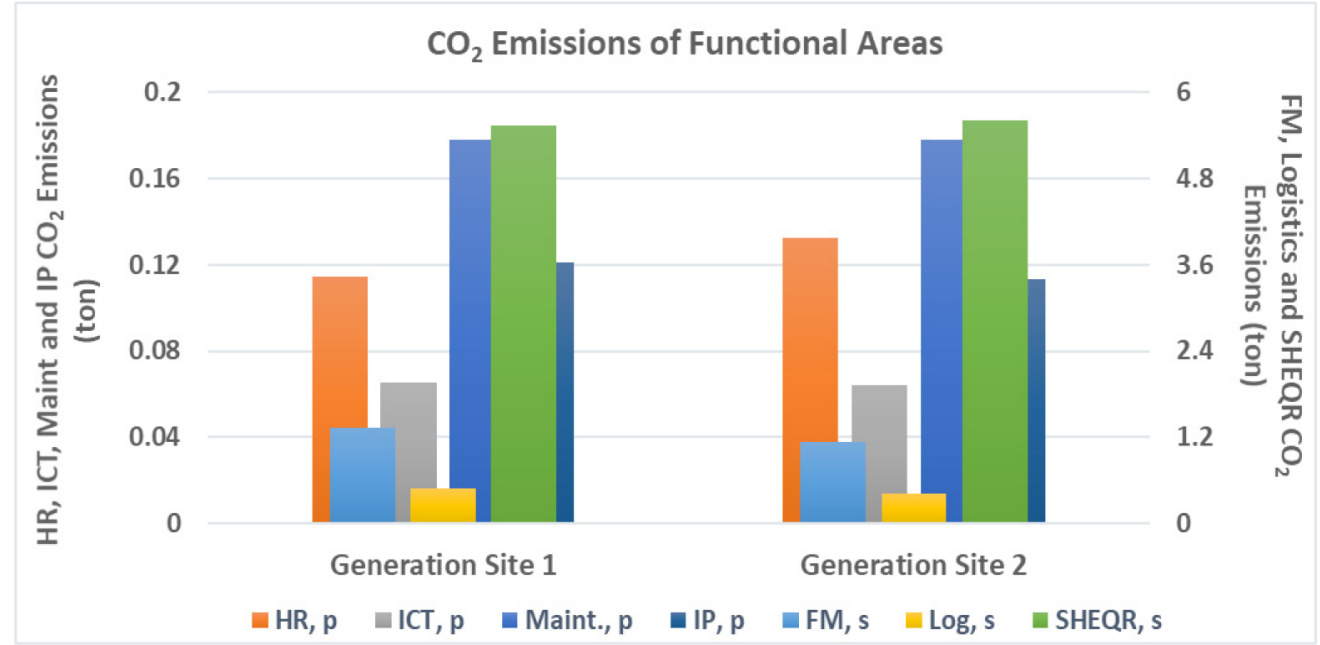

Figure 6. $\mathrm{CO}_{2}$ emissions of the various functional areas at each generation site

The $\mathrm{CO}_{2}$ emissions is directly proportional to the electrical energy demand, as detailed in Equation 2. The SHEQR, financial management and logistics functional areas are the top three contributors to the $\mathrm{CO}_{2}$ emissions.

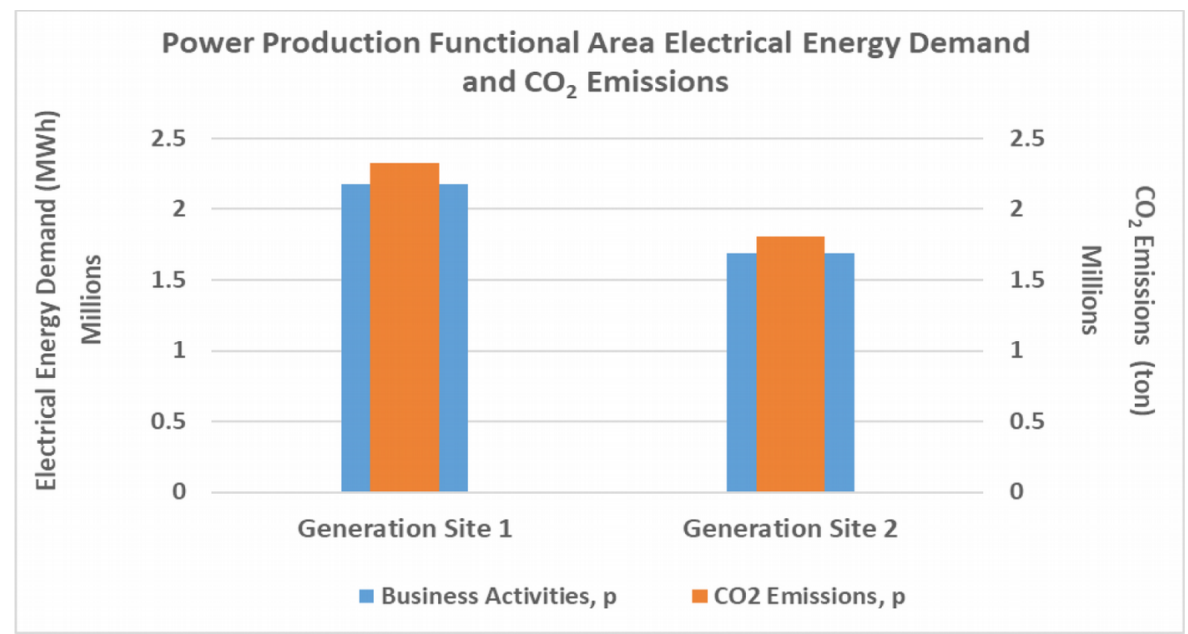

Figure 7. Electrical energy demand of the power production functional areas at each generation site

The high electrical energy demand of the power production function is attributed to the steam generation process equipment demand of pumps, compressors and fans. The steam generation process runs on a 24-hour basis. Figures 5 to 7 illustrate that the two generation sites have similar energy demand profiles for the various functional areas. This is due to both sites generating power via coal combustion and each site having six coal fired boilers and six steam turbines, resulting in a similar number of auxiliary equipment such as electrostatic precipitators, condensers, fans and pumps per boiler. Further to this, the number of personnel is similar; generation site 1 has 730 personnel and generation site 2 has 711 personnel.

For the corporate site, customer service management is the highest consumer of electrical energy demand, followed by strategy and financial management. The same trend is observed for the $\mathrm{CO}_{2}$ emissions of the corporate site.

The site level and functional area analyses reveal that the power production functional area of the generation sites is the largest contributor to the electrical energy demand. Hence an analysis of the equipment level energy demand is conducted for the steam generation business process (refer to the Appendix for the business process). Figure 9 illustrates the equipment having the highest electrical energy demand. 


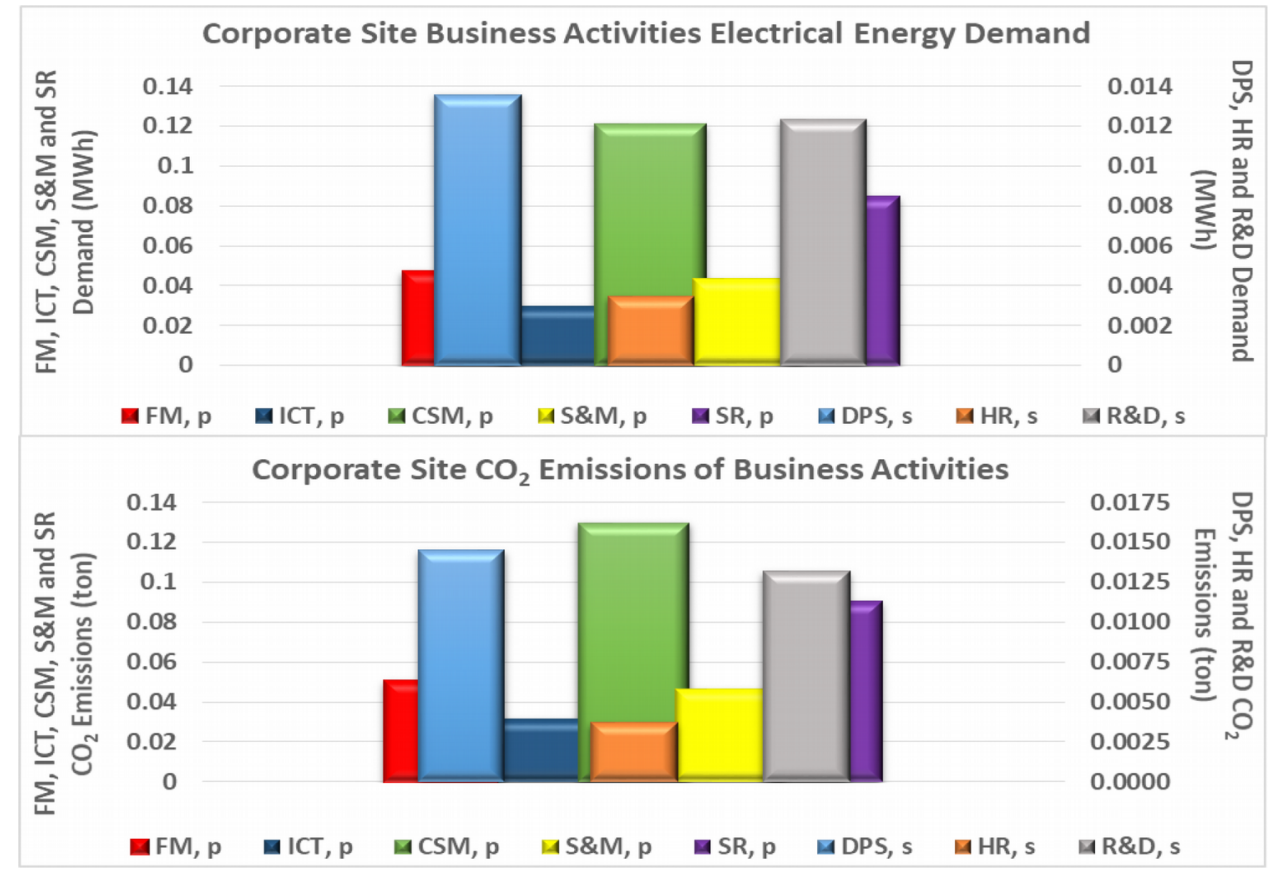

Figure 8. Electrical energy demand and $\mathrm{CO}_{2}$ emissions of the corporate site

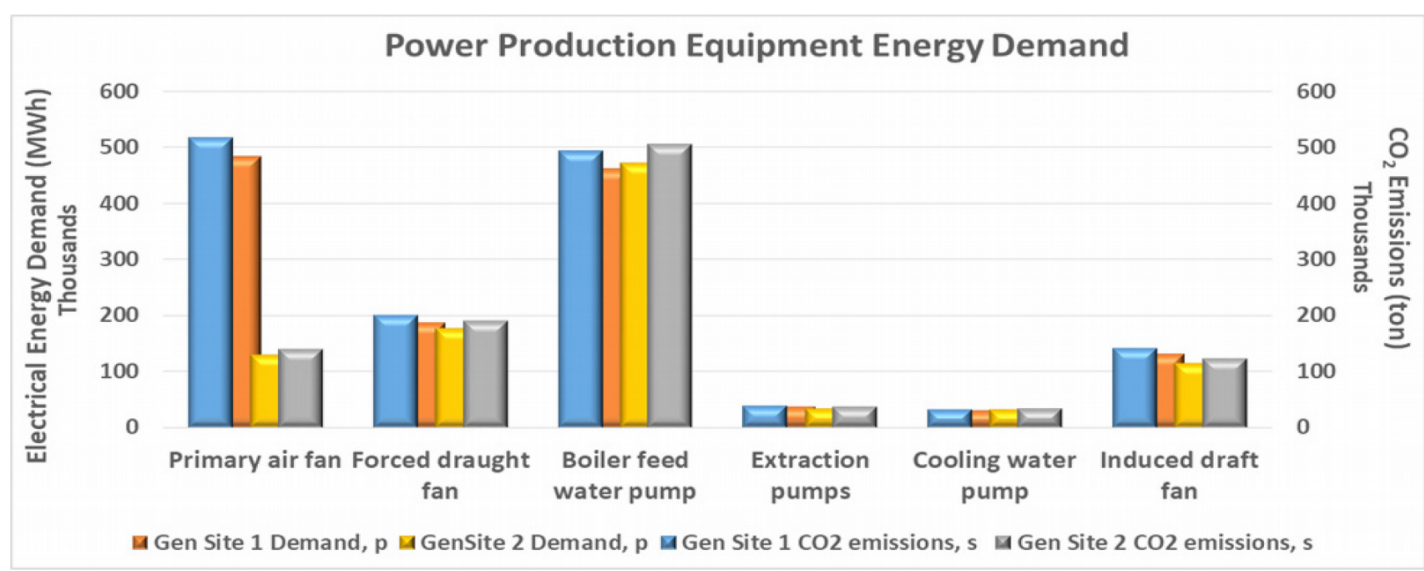

Figure 9. Equipment electrical energy demand of the steam generation process

The energy demand of most process equipment is similar for both sites, with the exception being the primary air fan. The difference is attributed to; generation site 1 consumes $22 \%$ more coal than generation site 2 and differing operational parameters, equipment efficiency and operational status.

The results illustrate the proposed energy model's capacity to simulate the electrical energy demand from a company level down to an equipment level. For this study, the two generation sites and specifically the power production functional areas are identified as the key contributors to the power company's energy demand and is the focus of optimisation.

\subsection{Optimization of the Baseline Energy Demand Via Scenario Analyses}

Optimisation is focused on the business areas having the greatest potential to reduce electrical energy demand and associated $\mathrm{CO}_{2}$ emissions. The baseline energy demand reveals the equipment of the steam generation process as the highest consumers of electrical energy. Figure 9 illustrates that all of the identified equipment have electric motors, hence Variable Frequency Drives (VFD) are selected for optimising the performance of pumps and fans. VFD regulates the speed of the motor based on the flows at that specific time, while conventional motors operate at a constant speed, typically at the higher speed range to accommodate all flow requirements. 
The business process were reviewed and the Industry 4.0 technologies of automation, Internet of Things (IoT), and Big Data Analytics (BDA) were selected for application.

- Automation: Utilising software and systems to process, transform and analyse data against key performance indicators such as planned generation output, emissions rate and boiler throughput. It is also used for the automatic generation of various reports.

- IoT: Equipment are fitted with Radio Frequency Identification (RFID) tags for real time acquisition of data. The data is analysed and information is transferred back to the equipment for self-adjustment in real time. IoT also facilitates the ability to access data and specific systems from anywhere and at any time.

- BDA: The analysis of large volumes of data for predictive purposes; equipment failures, maintenance intervals and optimum operational regimes.

These technologies are applied to the following business processes of the power production functional area:

- Production tracking: Tracks the performance of the power generation process against set production targets such as steam throughput and equipment performance indicators.

- Review Performance: Reviews the performance of the power generation functional area against key performance indicators such as planned generation output, emissions rate, and safety targets.

- Out of specification coal: Details the various steps to be executed when the coal is determined as being out of specification.

The application of the identified optimisation technologies to the aforementioned business processes requires significant capital, resource and time investment. Due to capital, resource and time constraints, the Design of Experiment (DOE) methodology is utilised is identifying the best optimisation option/s.

For the DOE analysis, there are four optimisation options; VFD, IoT, Automation and BDA, with each option having two levels; applied or not applied. This results in a $4^{2}$ factorial, with a total of 16 optimisation scenarios. The impact of the various optimisation scenarios on the electrical energy demand is illustrated in Figure 10.

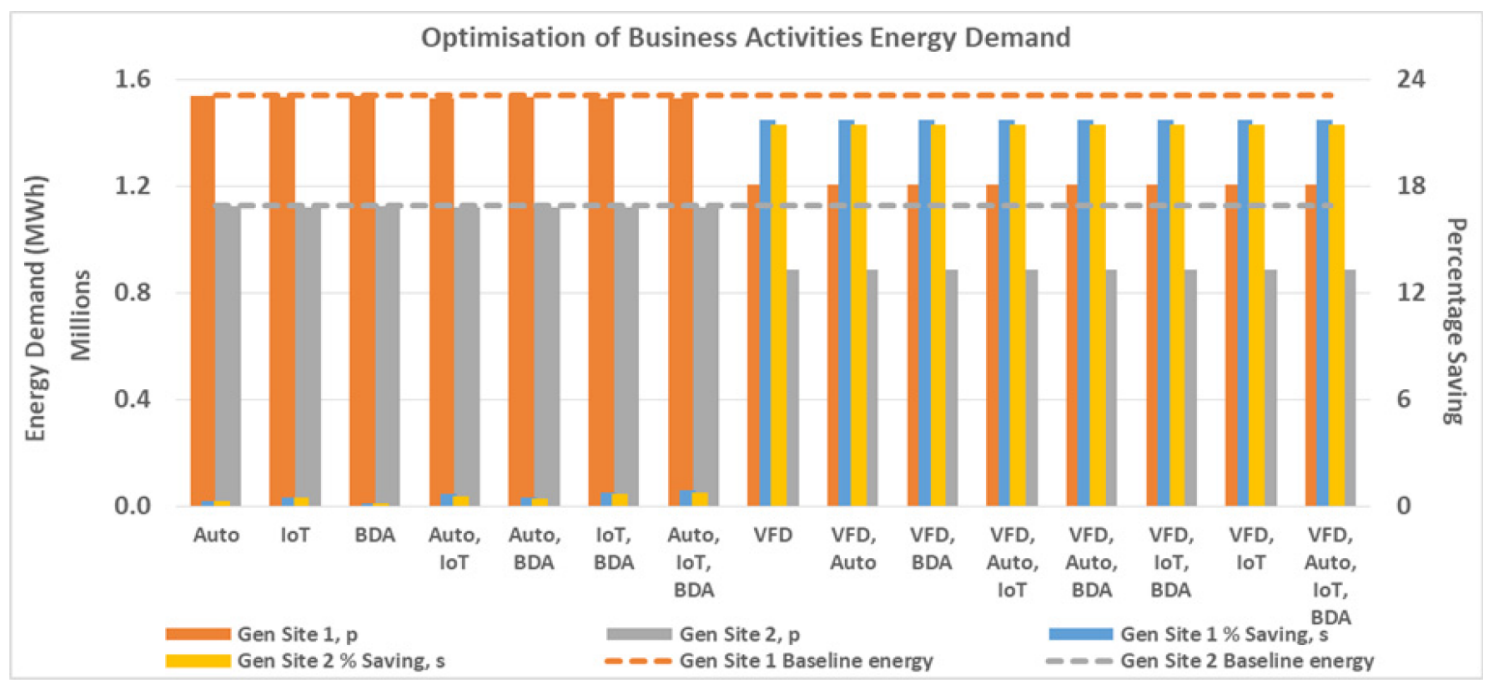

Figure 10. Impact of optimization technologies on electrical energy demand

The adoption of VFD results in an energy demand reduction of approximately $22 \%$ at each generation site. The impact of automation, IoT and $\mathrm{BDA}$ is low; $\mathrm{BDA}$ reduces the energy demand by $0.2 \%$ at each site and combined automation, $\mathrm{BDA}$ and IoT reduces the energy demand by $0.9 \%$ and $0.8 \%$ at generation sites 1 and 2 respectively. This is attributed to the technologies only being applied to a limited number of business processes. 


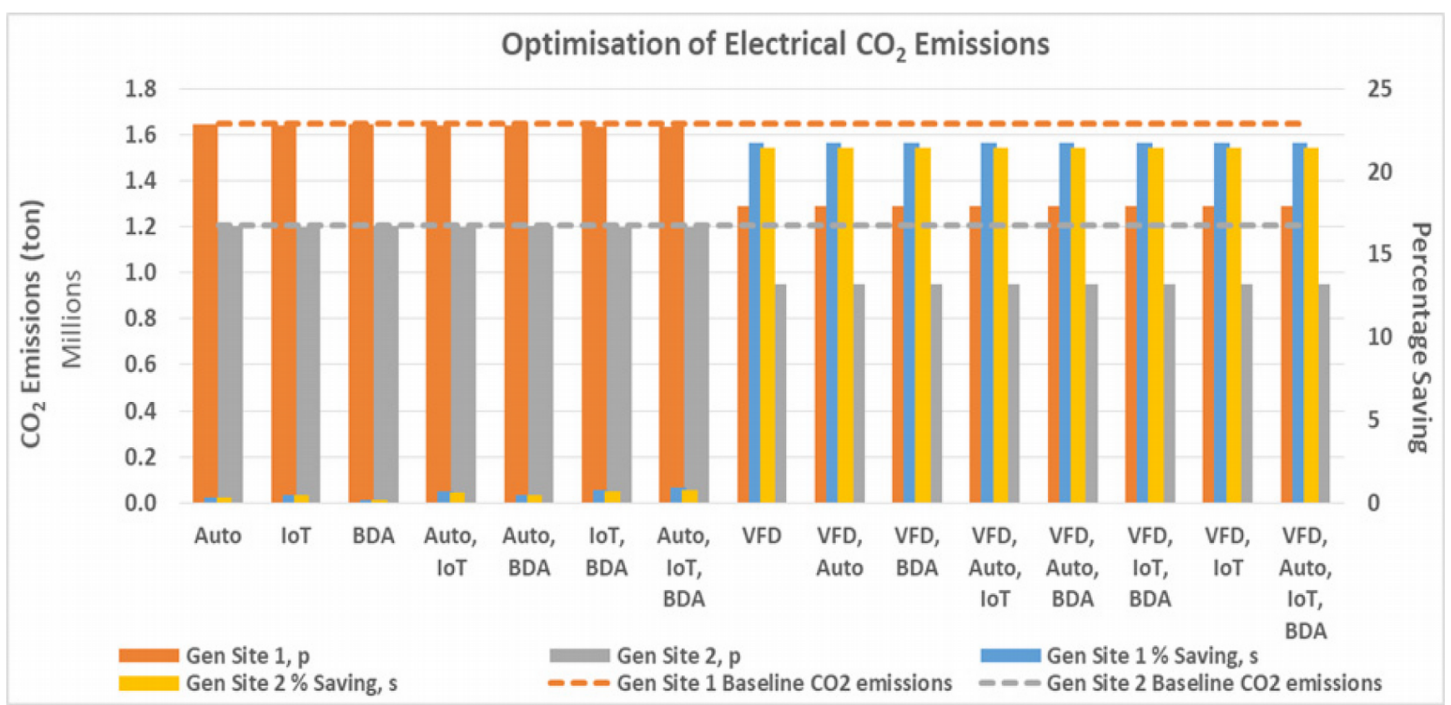

Figure 11. Impact of optimization technologies on $\mathrm{CO}_{2}$ emissions

The $\mathrm{CO}_{2}$ emission profile follows the same profile as the electrical energy demand. The adoption of the VFD results in a $\mathrm{CO}_{2}$ emissions reduction of approximately $22 \%$.

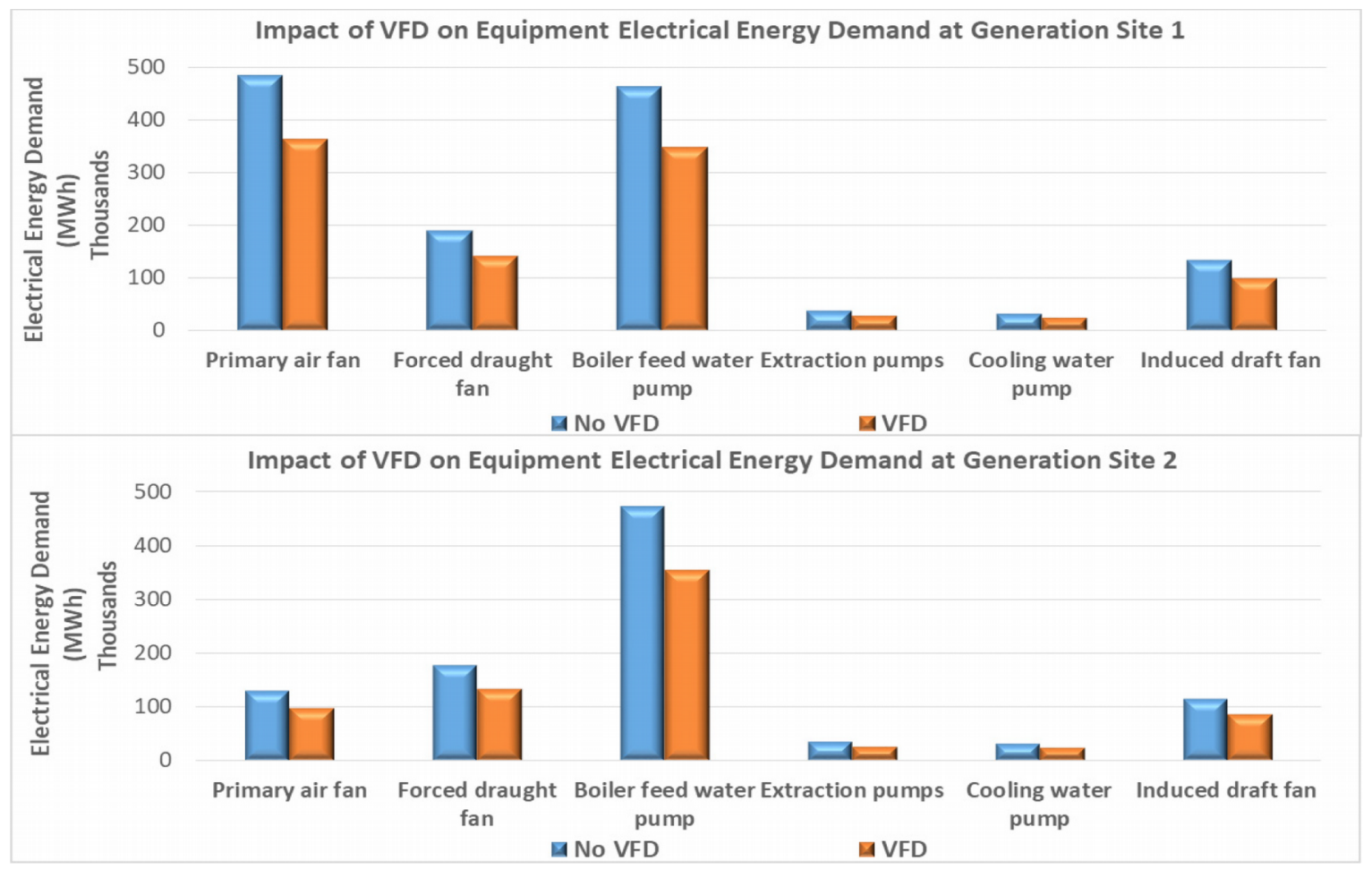

Figure 12. Impact of VFD on individual process equipment energy demand

Due to the high impact of VFD, the results are delineated to the equipment level. Figure 12 demonstrates that the adoption of VFD results in a $25 \%$ reduction in the energy demand of the individual equipment at each generation site.

The optimisation results demonstrate that adoption of VFD would enable the highest reduction in site electrical energy demand and $\mathrm{CO}_{2}$ emissions. Although the impact of IoT, BDA and automation was low (due to limited application), it demonstrated the potential of these technologies. 


\section{Conclusion}

The ability to fully quantify all aspects of energy utilisation, and $\mathrm{CO}_{2}$ emissions at a company is not a simple activity. The energy quantification is further challenged if there is a change at the business or operational level. This research adopts an activity based approach, where business activities are logically captured as business processes. The processes, once fully mapped are then converted to a Discrete Event Model. The model represents the entire business but more importantly is dynamic enough to accommodate changes in the business. The model is adopted to forecast optimisation. The model is also predictive and the research team integrate cleaner production and 4IR scenarios to guide decision makers on the impact to business energy consumption based on these optimisation options. The model is able to identify major energy users and opportunities.

The model is adopted to simulate and identify the impact of Cleaner production and 4IR interventions. The results provide insights into the ability to represent all business activities as business processes, and develop and validate a process centric Discrete Event Model. The model simulates optimisation scenarios and determines the impact to the coal to energy generation business.

The model as constituted forecasts the impact of CP and 4IR in the order of magnitude of between $0.2 \%$ for BDA with VSD potentially impacting the business at $22 \%$. The model has the capacity to forecast individual or any combination of CP and 4IR implementation. The model is activity based so changes in the business can be forecast effectively.

The research team embark on an ambitious model development, encompassing all business functions. The model delivered, together with associated results proves that business process models can be adopted for energy predictability and optimisation.

\section{Declaration of Conflicting Interests}

The authors declare no potential conflicts of interest with respect to the research, authorship, and/or publication of this article.

\section{Funding}

The authors received no financial support for the research, authorship, and/or publication of this article.

\section{References}

Agalianos, K., Ponis, S.T., Aretoulaki, E., Plakas, G., \& Efthymiou, O. (2020). Discrete event simulation and digital twins: Review and challenges for logistics. Procedia Manufacturing, 51, 1636-1641. https://doi.org/10.1016/i.promfg.2020.10.228

APQC (2015). Process Classification Framework V6.1.1. Available at: https://www.apqc.org/pcf

Aslani, A., \& Mohaghar, A. (2013). Business structure in renewable energy industry: Key areas. Renewable and Sustainable Energy Reviews, 27, 569-575. https://doi.org/10.1016/j.rser.2013.07.021

Aspen Technology Inc. (2021a). Aspen Energy Analyzer. Available at: https://www.aspentech.com/en/products/pages/aspen-energy-analyzer

Aspen Technology Inc. (2021b). Aspen Utilities User Guide. Available at: https://www.aspentech.com/en/products/engineering/aspen-utilities

Bhattacharyya, S.C., \& Timilsina, G.R. (2010). A review of energy system models. International Journal of Energy Sector Management, 4(4), 494-518. https://doi.org/10.1108/17506221011092742

Bititci, U.C., \& Muir, D. (1997). Business process definition: A bottom-up approach. Journal of Operations \& Production Management, 17, 365-374. https://doi.org/10.1108/01443579710159950

Bonate, P.L.A. (2001). A brief introduction to Monte Carlo Simulation. Clinical Pharmacokinetics, 40, 15-22. https://doi.org/10.2165/00003088-200140010-00002

Camargo, M., Dumas, M., \& Gonzalez-Rojas, O. (2020). Automated discovery of business process simulation models from event logs. Decision Support Systems, 134, 113284. https://doi.org/10.1016/j.dss.2020.113284 
Cataldao, A., Taisch, M., \& Stahl, B. (2013). Modelling, simulation and evaluation of energy consumptions for a manufacturing production line. IECON 2013 - 39th Annual Conference of the IEEE Industrial Electronics Society. 7537-7542. https://doi.org/10.1109/IECON.2013.6700388

Clark, R., Zucker, N., \& Urpelainen, J. (2020). The future of coal-fired power generation in Southeast Asia. Renewable and Sustainable Energy Reviews, 121, 109650. https://doi.org/10.1016/j.rser.2019.109650

Davis, R., \& Brabander, E. (2007). ARIS Design Platform: Getting started with BPM. London: Springer.

Ekyalimpa, R., Werner, M., Hague, S., AbouRizk, S., \& Porter, N. (2016). A combined discrete-continuous simulation model for analyzing train pedestrian interactions. Proceedings of the $2016 \mathrm{~W}$ inter Simulation Conference. https://doi.org/10.1109/WSC.2016.7822208

Feng, Y., Yang, B., Hou, Y., Duan, T., Yang, L., \& Wang, Y. (2021). Comparative environmental benefits of power generation from underground and surface coal gasification with carbon capture and storage. Journal of Cleaner Production, 310. https://doi.org/10.1016/j.jclepro.2021.127383

Gagarin, H., Sridhar, S., Lange, I., \& Bazilian, M.D. (2020). Considering non-power generation uses of coal in the United States. Renewable and Sustainable Energy Reviews, 124(December 2019). https://doi.org/10.1016/j.rser.2020.109790

GE (2019). GE PSLF. Available at: https://www.geenergyconsulting.com/practice-area/software-products/pslf

Guzman, G., Prasanna, A., Safarik, P., \& Tanwar, P. (2019). Unlocking the value of digital operations in electric-power generation (Issue October). McKinsey and Company.

Herbst, A., Tor, F., Reitze, F., \& Jochem, E. (2012). Introduction to energy systems modelling. Swiss Journal of Economics and Statistics, 148, 111-135. https://doi.org/10.1007/BF03399363

Hofmann, E., \& Rusch, M. (2017). Industry 4.0 and the current status as well as future prospects on logistics. Computers in Industry, 89, 23-34. https:/ / doi.org/10.1016/j.compind.2017.04.002

IEA (2017). Digitalization \& Energy. Available at: https://www.iea.org/reports/digitalisation-and-energy $\% 0 \mathrm{~A} \% 0 \mathrm{~A} \% 0 \mathrm{~A}$

IEA (2019). World Energy Outlook 2019 Executive Summary. Available at: https://iea.blob.core.windows.net/assets/1f6bf453-3317-4799-ae7b-9cc6429c81d8/English-WEO-2019-ES.pdf

IEA (2020a). Coal-Fired Power. Available at: https://www.iea.org/reports/coal-fired-power

IEA (2020b). Electricity. Available at: https://www.iea.org/fuels-and-technologies/electricity

Jebaraj, S., \& Iniyan, S. (2006). A review of energy models. Renewable and Sustainable Energy Reviews, 10(4), $281-311$. https://doi.org/10.1016/j.rser.2004.09.004

Keshari, A., Sonsale, A.N., Sharma, B.K., \& Pohekar, S.D. (2018). Discrete event simulation approach for energy efficient resource management in paper \& pulp industry. Procedia CIRP, 2-7.

https://doi.org/10.1016/j.procir.2018.08.324

Kohl, J., Spreng, S., \& Franke J. (2014). Discrete event simulation of individual energy consumption for product varieties. Procedia CIRP, 17, 517-522. https://doi.org/10.1016/j.procir.2014.01.088

Lang, S., Reggelin, T., Muller, B., \& Nahhas, A. (2021). Open-source discrete-event simulation software for applications in production and logistics: An alternative to commercial tools. Procedia Computer Science, 180, 978-987. https://doi.org/10.1016/j.procs.2021.01.349

May, G., Barletta, I., Stahl, B., \& Taisch, M. (2015). Energy Management in production: a novel method to develop key performance indicators for improving energy efficiency. Applied Energy, 149, 46-61.

https://doi.org/10.1016/j.apenergy.2015.03.065

Moeuf, A., Pellerin, R., Lamouri, S., Tamayo-Giraldo, S., \& Barbaray, R. (2017). The industrial management of SMEs in the era of Industry 4.0. International Journal of Production Research, 11181136.

https://doi.org/10.1080/00207543.2017.1372647 
Munsamy, M., Telukdarie, A., \& Fresner, J. (2019). Business process centric energy modelling. Business Process Management Journal, 25(7), 1867-1890. https://doi.org/doi.org/10.1108/BPMJ-08-2018-0217

Munsamy, M., \& Telukdarie, A. (2021). Business Process (4IR) Centric Optimization Modelling. Procedia Computer Science, 180, 581-590. https://doi.org/10.1016/j.procs.2021.01.279

Paulista, C.R., Peixoto, T.A., \& de Assis-Rangel, J.J. (2019). Modeling and discrete event simulation in industrial systems considering consumption and electrical energy generation. Journal of Cleaner Production, 224, 864-880. https://doi.org/10.1016/j.jclepro.2019.03.248

Peng, C., Chen, X., \& Yao, L. (2021). Research status and future of hydro-related sustainable complementary multi-energy power generation. Sustainable Futures, 3. https://doi.org/10.1016/j.sftr.2021.100042

Rentsch, R., \& Heinzel, C. (2015). Development of a Discrete Event Model for energy and resource efficient Milling. 15th CIRP Conference on Modelling of Machining Operations. https://doi.org/10.1016/j.procir.2015.03.085

SAP (2016). Process Hierarchy. Available at: https://wiki.scn.sap.com/wiki/display/SM/Process+Hierarchy

Sun, H., Edziah, B.K., Sun, C., \& Kporsu, A.K. (2021). Institutional quality and its spatial spillover effects on energy efficiency. Socio-Economic Planning Sciences, 101023. https://doi.org/10.1016/j.seps.2021.101023

Temponi, C., Bryant, M.D., \& Fernandez, B. (2009). Integration of business function models into an aggregate enterprise systems model. European Journal of Operational Research, 199(3), 793-800.

https://doi.org/10.1016/.j.jor.2008.08.007

United Nations (2020). The 17 Goals. Available at: https://sdgs.un.org/goals

Yao, J., Xiao, E., Jian, X., \& Shu, L. (2021). Service quality and the share of renewable energy in electricity generation. Utilities Policy, 69(101164). https://doi.org/10.1016/j.jup.2020.101164 


\section{Appendix}

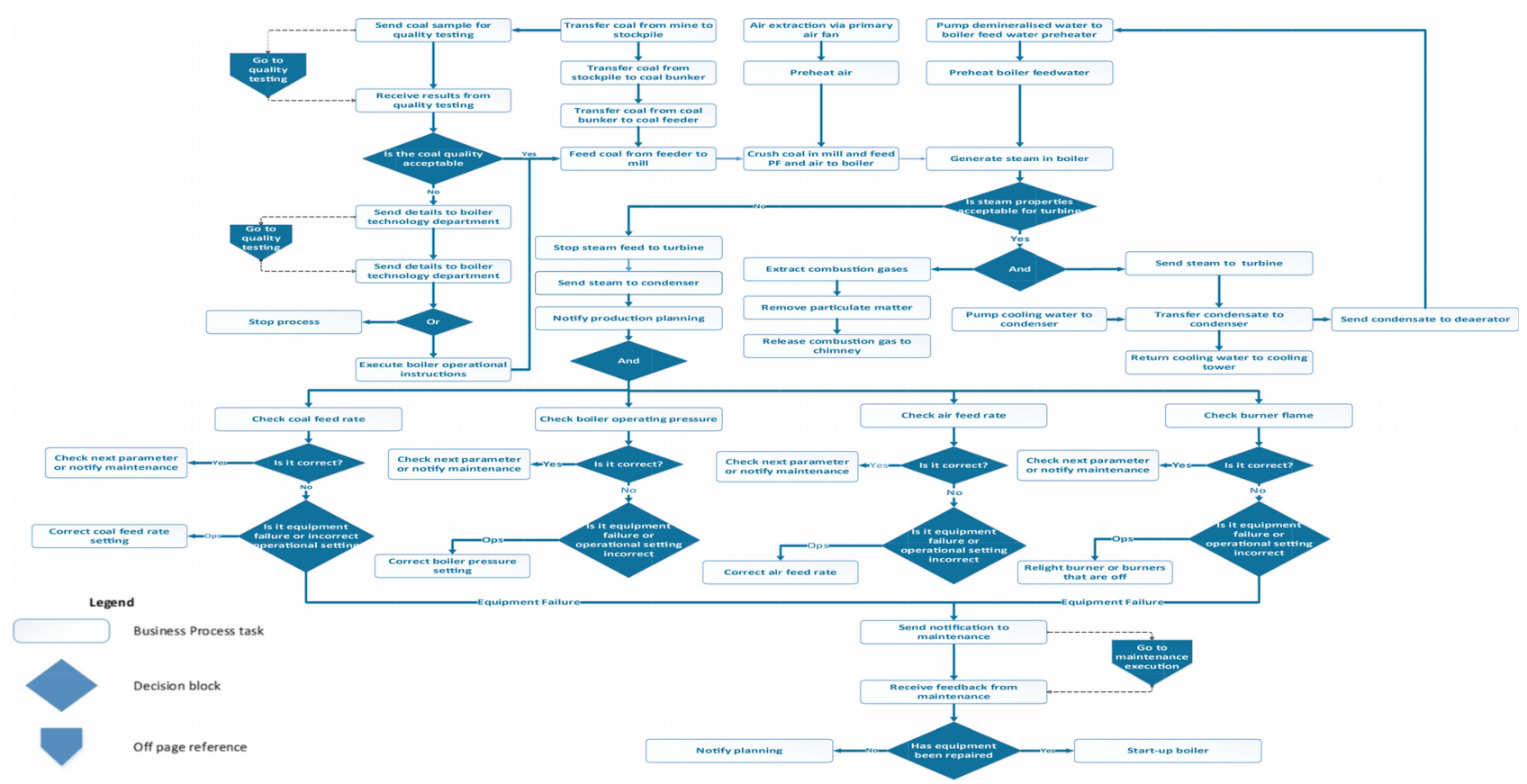

Figure A1: Steam generation business proces

Journal of Industrial Engineering and Management, 2022 (www.jiem.org)

\section{(@) $(1 \otimes$}

Article's contents are provided on an Attribution-Non Commercial 4.0 Creative commons International License. Readers are allowed to copy, distribute and communicate article's contents, provided the author's and Journal of Industrial Engineering and Management's names are included. It must not be used for commercial purposes. To see the complete license contents, please visit https://creativecommons.org/licenses/by-nc/4.0/. 